\title{
Digital Technologies within and beyond the Workplace: Impacts,
} Ambiguities, and Transformative Trends

\section{GUGLIELMO FALDETTA}

guglielmo.faldetta@unikore.it

Kore University of Enna

\section{MARIA LAURA FRIGOTTO}

marialaura.frigotto@unitn.it

University of Trento

\section{ALESSANDRA LAZAZZARA}

alessandra.lazazzara@unimi.it

University of Milan

\section{MICHELA MARCHIORI}

michela.marchiori@uniroma3.it

Roma Tre University

\section{MARIO PEZZILLO IACONO}

mario.pezzilloiacono@unicampania.it

University of Campania "Luigi Vanvitelli"

\section{ANNA CHIARA SCAPOLAN \\ annachiara.scapolan@unimore.it \\ University of Modena and Reggio Emilia}

Digital transformation (DT) is increasingly establishing itself as a constant theme in contemporary academic and practitioner conversations (Hanelt et al., 2020). Organisation scholars are attentive to the role and impact of digitalisation (Hinings, Gegenhuber and Greenwood, 2018), investigating how digital technologies affect individuals (Zuboff, 2015; 2019), organisations and professions (Foer, 2017), entire industries (Taplin, 2017), and societies (Morozov, 2011). There is no doubt that digitally-enabled arrangements permeate and reshape 
industries and fields, challenging organisational models, HRM practices, power structures and meaning systems (Alvesson and Kärreman, 2011). Moreover, the COVID-19 pandemic has accelerated the digitalisation of economy and organisations, anticipated many issues and transformations that would have taken longer to be addressed and posed unique demands in terms of conditions and scale of technology adoption at work (Wang et al., 2021). Thus, promoting theory and research development on this important substantive and methodological topic is therefore of foremost importance.

The focus of this issue is on the impacts, the ambiguities, and the transformative trends that emerge from the introduction of digital technologies into organisations. In the last few years some authors (e.g., Kane et al., 2015) have shown that the integration of digital technologies, such as social, mobile, analytics and cloud, is profoundly transforming organisational models, with specific reference to the way in which companies and public administration design new organisational forms, change inter-organisational ties, manage work practices and HRM processes. Issues such as internal commitment to digital progress, HRM lifecycle, talent attraction and retention, are strictly intertwined with ongoing digital transformation that modern organisations are experiencing (Orlikowski, 2007). The basic tenet of this revolution is to be found in the increased potential to connect organisational actors through digital information and communication technologies to organise work across conventional organisations. Furthermore, the reliance on 'big data' and algorithms in organisational strategies and models accentuate the need to explore the relationship between developments in digital technology and organisational changes. The emerging forms of network enterprises, extended districts, organisational platforms, holacracies, community of practices, and temporary organisations affect job tasks and roles and require a joint design of digital technologies, organisation and work.

At the same time, the empirical findings on the consequences of the adoption and use of digital technologies are still inconclusive, since several studies show that the pervasiveness of digital technologies may improve employees' productivity and quality of the work experience, but it may provoke also negative consequences for individual's well-being (e.g., Tarafdar et al., 2015). The disruptive effects of most advanced technological innovations on existing jobs are debated as well as the effect of digital forms of work on the autonomy and control of workers (Ales et al., 2018; Balsmeier and Woerter, 2019). On the one hand, technology and automation have led to the standardisation of behaviours and a decrease in the variety of activities and skills (Wang et al., 2021). On the other hand, employees have to struggle with the fast pace of innovations, and have to spend more time and effort renewing their technological skills. Moreover, they can be exposed to continuous changes in work conditions, to the risk of permanent availability, or the loss of boundaries between working and nonworking activities. In this sense, the concept of techno-stress has received growing attention from organisational scholars (Barley, Meyerson and Grodal, 2011).

To address these organisational issues related to digital transformation, many scholars (e.g., Verhoef et al., 2021) suggest not to rely on a single research field, that is, information systems or mainstream organisation studies, but to adopt an integrative approach able to catch the wide implications that digitalisation may have on organisations and people. Under this point of view, the analysis of the relations between digital technologies and organisations requires a multidisciplinary, critical, and innovative approach, in order to shed a light on the transformative - or even revolutionary - trends, as well as on the negative effects or the ambiguities and paradoxical results - that characterise digitalised organisations. 
Six research papers constitute this issue, which have been evaluated through a standard blind review process in order to ensure theoretical and methodological rigor endured. The papers analyse the issue of "Digital Technologies within and beyond the Workplace: Impacts, Ambiguities, and Transformative Trends" in different contexts as well as with different methodological and epistemological approaches. Taken together, they depict an original and relevant snapshot of the relationship between organisational design and digitalisation in contemporary organisations.

The article "The Transformation of Work in the COVID-19 Era" by Anna Comacchio explores how the pandemics transformed work design and work practices by accelerating virtuality and connectivity towards new directions that will probably overcome the COVID-19 era itself. Major risks, as well as opportunities for future research related to this rapid transformation, are discussed. Among risks, hyper-connection and work-life permeability related to the blurred distinction between working and non-working space are envisioned. Also, at the time of writing, at least two kinds of fatigue were already manifest. They are the 'Zoom fatigue' and the fatigue from hyper-efficiency due to the disappearance of mobility and switching times from one meeting to the other. Ergonomics is also a risk triggered by settings that were meant to serve the housing and not working purposes. Among future research streams, the article suggests elaborating on the impact of the higher degree of autonomy enhanced by decentralisation on productivity, on workers' loneliness and the dissolution of informal social relations, and the role of the physical office in 'healing' and reconstructing the organisational social fabric.

The article by Angelo Gasparre, Luca Beltrametti and Luca Persico, "Industry 4.0 and Digital Innovation in Manufacturing: State of the Art Technology and Future Prospects in the Italian Mechanical Engineering Sector", shows the magnitude of a phenomenon that has been undoubtedly subject to some excessive rhetoric. The article reports the results of a survey performed by means of a questionnaire administered to a large sample of Italian companies operating in the mechanical engineering sector. The first finding concerns the degree to which Industry 4.0 technologies are currently adopted by the sampled firms. $64 \%$ of firms are identified as adopters and $34 \%$ as non-adopters. Results show that the percentage of adopters increases among larger companies and more export-oriented firms. Moreover, adopters show a higher percentage of graduate employees and cooperate more with research and academic institutions. Findings show also which technologies are mainly adopted and by which organisational units. The regression analysis on the determinants of adoption confirms the role played by firm size, internationalisation, ownership, and orientation toward Industry 4.0. Family businesses as well as firms more focused on the potential threats and risks of Industry 4.0 are less inclined to adoption. Another interesting result is the fact that non-adopters are not planning any significant investment in industry 4.0 in the coming years, with the only exception being cybersecurity, which could mean a lack of strategy which will probably lead to an ever-widening gap between adopters and non-adopters in the future. This is something that industrial and political leaders should take note.

The article "The Adoption of Discontinuous Technologies in the Time of COVID-19: Criticisms for Micro Family Businesses", by Roberta Oppedisano, analyses the dynamics of the adoption of technology in micro family businesses at the time of COVID-19. The aim of this study is to investigate the influence of the family and of the COVID-19 emergency on the adoption of discontinuous technologies. Using a sample of 20 micro-enterprises from southern Italy, the author conducts a qualitative analysis, identifying the micro-level factors affecting 
the decision to adopt discontinuous technology in order to detect how innovation in the context of the family business takes place in a different and distinctive way.

The article by Luca Pareschi titled "Is It Smart Working? An Analysis of the Public Discourse about Teleworking in Italy during the COVID-19 Pandemic" deals with a topic - working from home - that has attracted considerable attention both in the public and academic debate. Drawing on the neo-institutional theory, the author analyses how working from home was framed in the discursive space composed by Italian newspapers. More specifically, using the Topic Modelling technique, the author performed a text analysis on the articles published on seven national newspapers during the first two months of the COVID-19 pandemic, when in Italy a total lockdown was imposed and working from home became a forced choice for several enterprises and employees. Fourteen topics representing discourses around working from home has been identified. The article illustrates how these topics have contributed to the institutionalisation of working from home as a legitimate way of working. Moreover, from the analysis of these topics over time, the author identifies two distinct phases of this institutional process, where a 'dealing with the exceptional' phase has been followed by a 'new normal phase', which has been paving the way for determining what of such contested way of working can remain after the COVID-19 pandemic.

By taking an organisational perspective, Rocco Reina, Marzia Ventura, Concetta L. Cristofaro, and Teresa A.R. Gentile, in their article "Mobile Application for Healthcare: The Case of COVID-19 in Mobile Apps", propose a framework to analyse the relationship between ICT and self-management in the healthcare sector in Italy. The main purpose of the paper is to understand the features and functionalities of the COVID-19 mApps currently available in the widely used smartphone applications stores, such as Play Store and iTunes. The research found $71 \mathrm{mApps}$ operating in the principal stores, focusing on the underlining features and organisational aspects useful for making users more responsible and enabling selfmanagement regarding their own health.

The article titled "Mechanisms to Engage an Online Community in Crowdsourcing: Insights from an Idea Contest in Training" by Adriano Solidoro, Francesco Aleotti, Gianluigi Viscusi, Christopher L. Tucci, and Davide Diamantini is focused on how to design a crowdsourcing initiative with an emphasis on the mechanisms fostering the engagement of an online community. More specifically, the authors analyse a crowdsourcing experience designed for a large community of professional trainers in order to better understand which factors may foster participants' engagement. Since participants' behaviour and quality of the content produced constitute a prerequisite for crowdsourcing performance, this study may have many practical implications in terms of how organisations may involve stakeholders such as workers, managers, citizens, customers, and policymakers in order to accelerate innovation and problem-solving.

In summary, we hope that readers enjoy these articles as much as we have. We think this thematic issue offers different interesting perspectives on the issue of digital transformation, thus stimulating the ongoing academic and practitioner debate. In these papers, we see a variety of topics, theoretical perspectives and methodological approaches, reflecting the diversity that exists in this field. What is also apparent throughout this thematic issue is that this area remains relatively under-researched. We therefore hope that the readers of this thematic issue will identify avenues for further investigation as a result of this thematic issue and will continue forward to develop and expand the evidence base for organisational design in the digital age. 
In the preparation of this thematic issue, the authors have received help from a number of referees, whom the authors would like to thank. In addition, we would like to take this opportunity to thank Prof. Luigi Maria Sicca for giving us the opportunity to serve as guest editors for the thematic issues. Finally, we would like to thank ASSIOA Associazione Italiana di Organizzazione Aziendale - who supported the design and promotion of this thematic issue.

\section{Keywords}

Digital technologies; Covid-19; Workplace; Digital transformation

\section{References}

Ales, E., Curzi, Y., Fabbri, T., Rymkevich, O., Senatori, I., and Solinas, G. (2018), Working in digital and smart organizations, Basingstoke: Palgrave McMillan.

Alvesson, M., and Kärreman, D. (2011), “Decolonializing discourse: Critical reflections on organizational discourse analysis", Human Relations, 64 (9): 1121-1146.

Balsmeier, B., and Woerter, M. (2019), “Is this time different? How digitalization influences job creation and destruction", Research Policy, 48 (8): 103765.

Barley, S.R., Meyerson, D. E., and Grodal, S. (2011), "E-mail as a source and symbol of stress", Organization Science, 22 (4): 887-906.

Foer, F. (2017), World without mind: The existential threat of big tech, New York, NY: Penguin Press.

Hanelt, A., Bohnsack, R., Marz, D., and Antunes Marante, C. (2020), "A systematic review of the literature on digital transformation: Insights and implications for strategy and organizational change", Journal of Management Studies. DOI: 10.1111/joms.12639.

Hinings, C.R., Gegenhuber, T., and Greenwood, R. (2018), “Digital innovation and transformation: An institutional perspective", Information and Organization, 28 (1): 52-61.

Kane, G.C., Palmer, D., Phillips A.N., Kiron, D., and Buckley, N. (2015), “Strategy, not technology, drives digital transformation", MIT Sloan Management Review, 1-25. http://sloanreview.mit.edu/digital2015.

Morozov, E. (2011), The net delusion: The dark side of Internet freedom, New York, NJ: PublicAffairs.

Orlikowski, W.J. (2007), “Sociomaterial practices: Exploring technology at work”, Organization Studies, 28 (9): 1435-1448.

Taplin, J. (2017), Move fast and break things. How Facebook, Google, and Amazon cornered culture and undermined democracy, New York, NY: Little, Brown and Company.

Tarafdar, M., Darcy, J., Turel, O., and Gupta, A. (2015), “The dark side of information technology", MIT Sloan Management Review, 56 (2): 61-70.

Verhoef, P.C., Broekhuizen, T., Bart, Y., Bhattacharya, A., Dong, J.Q., Fabian, N., and Haenlein, M. (2021), "Digital transformation: A multidisciplinary reflection and research agenda", Journal of Business Research, 122: 889-901.

Wang, B., Liu, Y., Qian, J., and Parker, S.K. (2021), “Achieving effective remote working during the COVID-19 pandemic: A work design perspective", Applied Psychology, 70 (1): 16-59. 
Zuboff, S. (2015), "Big other: Surveillance capitalism and the prospects of an information civilization", Journal of Information Technology, 30 (1): 75-89.

Zuboff, S. (2019), The age of surveillance capitalism. The fight for a human future at the new frontier of power, New York, NY: PublicAffairs. 